\title{
O ERGODESIGN E A ENGENHARIA DE USABILIDADE DE INTERFACES, COMO FACILITADORES PARA OS USUÁRIOS NA BUSCA DE INFORMAÇÕES
}

\author{
SCHULENBURG, Haro Ristow Wippel. Msc. \\ Universidade Federal De Santa Catarina - UFSC \\ haro@harodesigner.com.br \\ VELA, João Carlos Vela. Msc \\ Universidade Federal De Santa Catarina - UFSC \\ joao.vela1@gmail.com \\ FIALHO, Francisco Antônio Pereira - Dr. \\ Universidade Federal De Santa Catarina - UFSC \\ fapfialho@gmail.com \\ TRISKA, Ricardo. Dr. \\ Universidade Federal De Santa Catarina - UFSC \\ ricardo.triska@gmail.com
}

Resumo: O presente artigo tem a intenção de realizar uma abordagem aos estudos de ergodesign e a engenharia de usabilidade com foco em interfaces, demonstrando suas importâncias como meios facilitadores para a busca de informações realizadas pelos usuários. Para desenvolvimento deste processo, é necessário um conhecimento e noção do corpo de regras, de diretrizes e procedimentos usados para selecionar, organizar e manipular dados, reconhecendo assim, características da boa informação. Além disso, conceitos de ergodesign e também da interdisciplinaridade da engenharia de usabilidade, expõem de maneira intrínseca a integração do perfil do usuário com o ciclo estrutural em um projeto de interface. 0 conceito do processo humano de busca por informação também é abordado em três aspectos: cognitivo, afetivo e físico. Estes, com foco centrado no usuário, se iniciam com o reconhecimento e a aceitação do problema e continua até que o problema seja resolvido. Além de um levantamento teórico dos temas mencionados até então, um dos principais objetivos é demonstrar de maneira sistêmica a relação do ergodesign e da engenharia de usabilidade, com o processo de busca de informações. Podendo ser efetuado ao longo de linhas paralelas de progresso, aproveitando as oportunidades que surjam de resultados aleatórios ou intermediários. Deixando claro que o processo do usuário na busca de informações é dinâmica e orientado à ação.

Palavras-chave: ergodesign, usabilidade, busca de informações. 


\begin{abstract}
This article approaches the areas of ergodesign and usability engineering with focus on interfaces, demonstrating their importance as enablers of searching information for the users. To do that, knowledge and sense of rules, guidelines and procedures used to select, organize and manipulate data, thus recognizing, characteristics of good information is needed. Moreover, concepts of ergodesign and also the interdisciplinarity of usability engineering, expose intrinsically the integration between user profile and the structural cycle in a interface design. The information seeking process is also discussed in three aspects : cognitive, affective and physical. These, with user-centric focus, start with the recognition and acceptance of the problem and continues until the problem is resolved. In addition to a theoretical survey of the issues mentioned previously, the main goal here is to demonstrate, in a systemic way, the relationship between ergodesign, usability engineering and the process of finding information. That can be made along parallel lines of progress, seizing opportunities that arise from random outcomes or intermediates, making clear that the user process in the search for information is dynamic and action-oriented.
\end{abstract}

Keywords: ergodesign, usability, search for information.

\title{
1. INTRODUÇÃO
}

O termo Ergodesign nomeia a união da Ergonomia com o Design. Segundo Grandjean (1984), "se uma aplicação dos princípios da Ergonomia ao processo de Design é implementada, o resultado deve ser um produto atrativo e também amigável". Já para Yap et al. (1997), Ergodesign significa a fusão dos focos teóricos e práticos das duas disciplinas. Com isso, observa-se, que à medida que os sistemas se tornam mais complexos, fica cada vez mais difícil estabelecer diferenças entre estas duas disciplinas. Pode-se concluir então, que o Ergodesign possui uma foco macroergonômico criativo, que busca a conciliação entre os atributos humanos e sistêmicos simultaneamente com o conceito e desenvolvimento do design.

O Ergodesign em um projeto de interface gráfica inclui várias contribuições, tendo como foco principal o usuário. Aliada ao design, ela busca aperfeiçoar a transmissão de informações e promover a usabilidade. Moraes e Mont'alvão (1998) escrevem que na programação visual a ergonomia objetiva a otimização do sistema e o melhoramento da sua eficiência, assim como a da humana.

Segundo Cybis et al. (1998), em virtude do processo de informatização da sociedade, a ergonomia passa a ter grande importância para a qualidade de vida, sendo percebida quando leigos passam a ter acesso aos dispositivos informatizados.

Uma interface gráfica ergonômica possui maior receptividade do que uma alienada somente aos seus conceitos, permitindo que o usuário interaja com informações mais claras, objetivas e agradáveis. A concepção de uma interface gráfica deve integrar critérios ergonômicos desde sua fase inicial, de forma a assegurar um desenvolvimento adequado aos processos interativos entre homem e computador.

Uma preocupação do design de interação é desenvolver produtos interativos utilizáveis, que sejam, portanto, fáceis de aprender, eficazes no uso e que condicionem uma experiência agradável ao usuário (PREECE et al., 2007). De uma maneira sintetizada, a ergonomia visa à adaptação dessas tarefas ao homem. 
Dul e Weerdmeester (2004) escrevem que o uso da ergonomia contribui para solucionar problemas sociais relacionados à saúde, segurança, conforto e eficiência e se aplica ao projeto de máquinas, equipamentos, sistemas ou tarefas.

Segundo Moraes e Mont'alvão (1998), ergonomia é o estudo científico das relações entre homem e sistema, tendo como objetivo aumentar o desempenho, 0 conforto e a qualidade de vida nesse processo. Cybis et al. $(1998$, p. 2) escreve que "a ergonomia se vale dos conhecimentos sobre o homem no trabalho".

lida $(2000$, p. 1) define ergonomia como "o estudo da adaptação do trabalho ao homem". Ele coloca o trabalho como algo abrangente, presente em toda relação entre isto e o homem. Dessa forma, a pesquisa aqui abordada demonstra o processo de interação entre homem e interface, pois, conforme Kroemer e Grandjean (2005), ambos mantêm uma relação recíproca.

Dentre os estudos ergonômicos Montmollin (1990) aborda características psicofisiológicas, que dizem respeito, principalmente, conforme, à atividade visual e auditiva, ao tato, aos tempos de reação, bem como a percepção visual, a atenção e a vigilância. Ainda, segundo o autor, estes conhecimentos permitem, por exemplo, a adaptação conveniente de luminosidade, contrastes e reflexos, a legibilidade dos caracteres e a discriminação de símbolos pictográficos.

Dentre todas essas características, tem-se um destaque para a visão. Ela é o órgão do sentido mais importante, seja no trabalho ou na vida diária, tendo como principais características a acuidade visual (discriminação de detalhes), a acomodação (capacidade de foco), a convergência (movimentação sincronizada dos olhos) e a percepção das cores (sensibilidade à luz) (IIDA, 2000).

Diante o exposto, o designer gráfico, que lida com a construção de imagens e os processos que envolvem sua interação, tem perante a ergonomia, quase que automaticamente, o compromisso em integrá-la na sua atuação, já que tem-se também, por meio da percepção visual, o sentido que conecta o design gráfico aos conceitos ergonômicos.

\section{ENGENHARIA DE USABILIDADE}

De acordo com Santos (2007), a expressão "engenharia de usabilidade" é utilizada para se referir aos conceitos e técnicas para planejamento, atingimento e verificação de objetivos para uma usabilidade sistêmica. Além disso, é uma disciplina que oferece métodos estruturados para atingir a usabilidade em um projeto de interface.

A disponibilização de informação em um meio exige uma organização desse conteúdo, de modo a garantir o acesso das pessoas. Imaginar uma rede, como a Internet, sem essa preocupação é o mesmo que imaginar que todos os livros do mundo estivessem num só livro sem sumário. Encontrar o que se busca seria uma tarefa árdua nesse "mar de tanta informação" (ROSA; MORAES, 2008).

O usuário deve percorrer caminhos curtos, entendendo onde ele está e para onde pode ir, ou seja, dentre a quantidade de informações e a variedade de ferramentas e elementos disponíveis, a existência de uma organização que viabilize a navegação guiada é necessária para que o usuário tenha visibilidade e sabia utilizar o sistema e se localizar (ANDRADE, 2007). 
Em função disso, o constante crescimento da informação disponibilizada na rede, juntamente com o aumento da quantidade de pessoas conectadas, demonstram a importância que a arquitetura da informação vem apresentando (MEMÓRIA, 2003).

Conforme Rosa e Moraes (2008), a arquitetura da informação, inserida em uma etapa da engenharia de usabilidade, possibilita que os usuários encontrem intuitivamente o que precisam por meio da combinação de navegação com procura aplicada às estradas da informação e aos atalhos, pontes e conexões, construídos pelo arquiteto da informação.

Os designers de interface são também arquitetos da informação, fazendo com que a arquitetura seja acessível (LYNCH; HORTON, 2004). Fuentes (2006) acredita que por se tratar da escolha de navegação e interação adequadas, o designer de interface tem mais haver com a arquitetura da informação do que com gráficos.

Dessa forma, o designer gráfico participa ativamente no processo de desenvolvimento da arquitetura da informação e por isso é um assunto pertinente à concepção de uma interface gráfica.

A engenharia de usabilidade precisa ser bem projetada para garantir que as tarefas executadas pelos usuários sejam concluídas, poupando seu tempo e evitando que fiquem frustrados por não encontrarem o que buscavam (MEMÓRIA, 2003). Para garantir a eficiência nesse processo, a modelagem e a representação da arquitetura competem, segundo Rosa e Moraes (2008), a definição de um vocabulário de termos padronizados visando obter consistência ao longo do conteúdo e um mapa metafórico objetivando a representação da sua estrutura.

A figura 1 demonstra um diagrama do tipo pente, útil para os meios que funcionam verticalmente, como neste documento

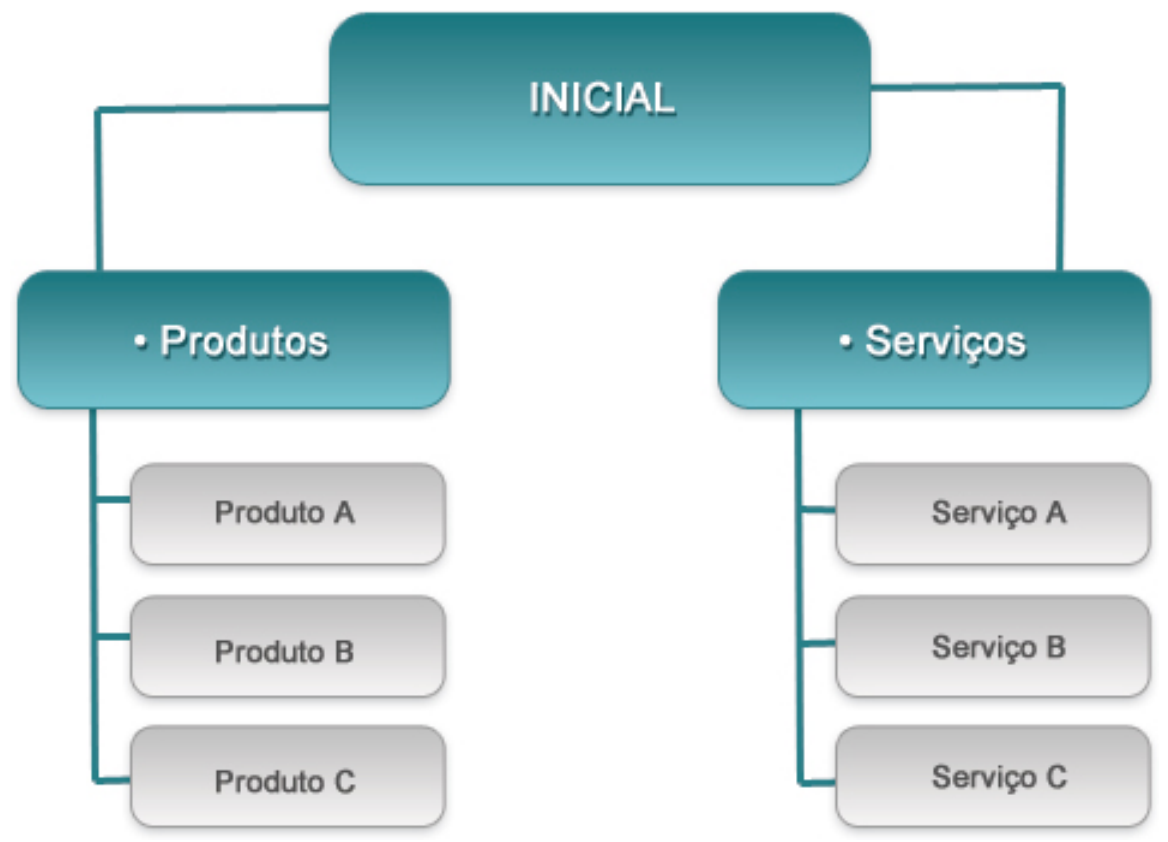

Figura 1 - Mapa em Pente

Fonte: Imagem desenvolvida baseada em dados de Rosa e Moraes (2008, p.82)

O diagrama é descrito por Domingues (2002) como um fluxograma de navegação que permite circular pelas informações, como formas, sons e textos, disponíveis nas arquiteturas da hipermídia. Todavia, estes elementos não devem ser 
pensados durante a concepção da arquitetura da informação. Cabe nesta etapa apenas a tarefa de planejar uma estrutura informacional que seja intuitiva e por isso condicione ao usuário a capacidade de entender o caminho a ser percorrido para encontrar o que ele busca no meio virtual.

\section{USABILIDADE DE INTERFACES}

Em toda interação com uma interface gráfica, existe uma usabilidade oferecida por esse suporte. A sua configuração, neste ponto, facilita a realização de tarefas importantes pelo uso de ferramentas como botões, links, campos e barras de rolagem.

A usabilidade condiciona uma lógica de funcionamento, ela caracteriza, segundo Cybis et al. (2007), o uso dos programas e das aplicações. Ela capacita um sistema, em termos fucionais-humanos, o uso fácil e com eficácia, garantindo que o segmento específico de usuários focados poderão reconhecer e interagir satisfatoriamente com as funções direcionadas as suas necessidades (ROSA; MORAES, 2008).

Conforme Preece et al. (2007), a usabilidade é o fator que assegura, na perspectiva do usuário, a utilização dos produtos de forma fácil, eficiente e agradável. Dul e Weerdmeester (2004) escrevem que um usuário aciona um controle sob uma determinada expectativa, e caso seu efeito não ocorra, podem acontecer problemas. "O design de uma interface não deve colocar barreiras de nenhum tipo à acessibilidade e à navegabilidade, a menos que a dificuldade seja um componente almejado na (in)comunicação pretendida" (FUENTES, 2006, p. 104).

A usabilidade assume certa importância nos últimos tempos, pois, em função da inclusão digital, uma avalanche de usuários novatos ingressa à rede, principalmente idosos que estão em fuga das dificuldades de locomoção, violência urbana e espaços públicos mal cuidados (ROSA; MORAES, 2008).

Fuentes (2006) destaca a importância do entendimento das plataformas tecnológicas para que os usuários "normais", como ele chama os usuários que possuem equipamento mediano, supostamente inferior ao dos desenvolvedores, possam navegar naturalmente por uma interface, sem barreiras.

Para Memória (2003) o usuário pouparia tempo se as interfaces tivessem elementos mais padronizados, pois facilitaria a utilização e o aprendizado. A explicação disto é suscitada a partir da observação de Montmollin (1990): os usuários utilizam mais a indução do que a lógica dedutiva durante uma operação.

Segundo Montmollin (1990, p. 109), "a semelhança com uma situação anterior substitui a análise raciocinada". Sendo assim, elementos de navegação que se assemelham a outros interfaces possuem maiores chances de serem usados de acordo com o qual foram projetados.

Para otimizar os sistemas interativos, Preece et al. (2007) propõe metas de usabilidade, mostradas na figura 2. 


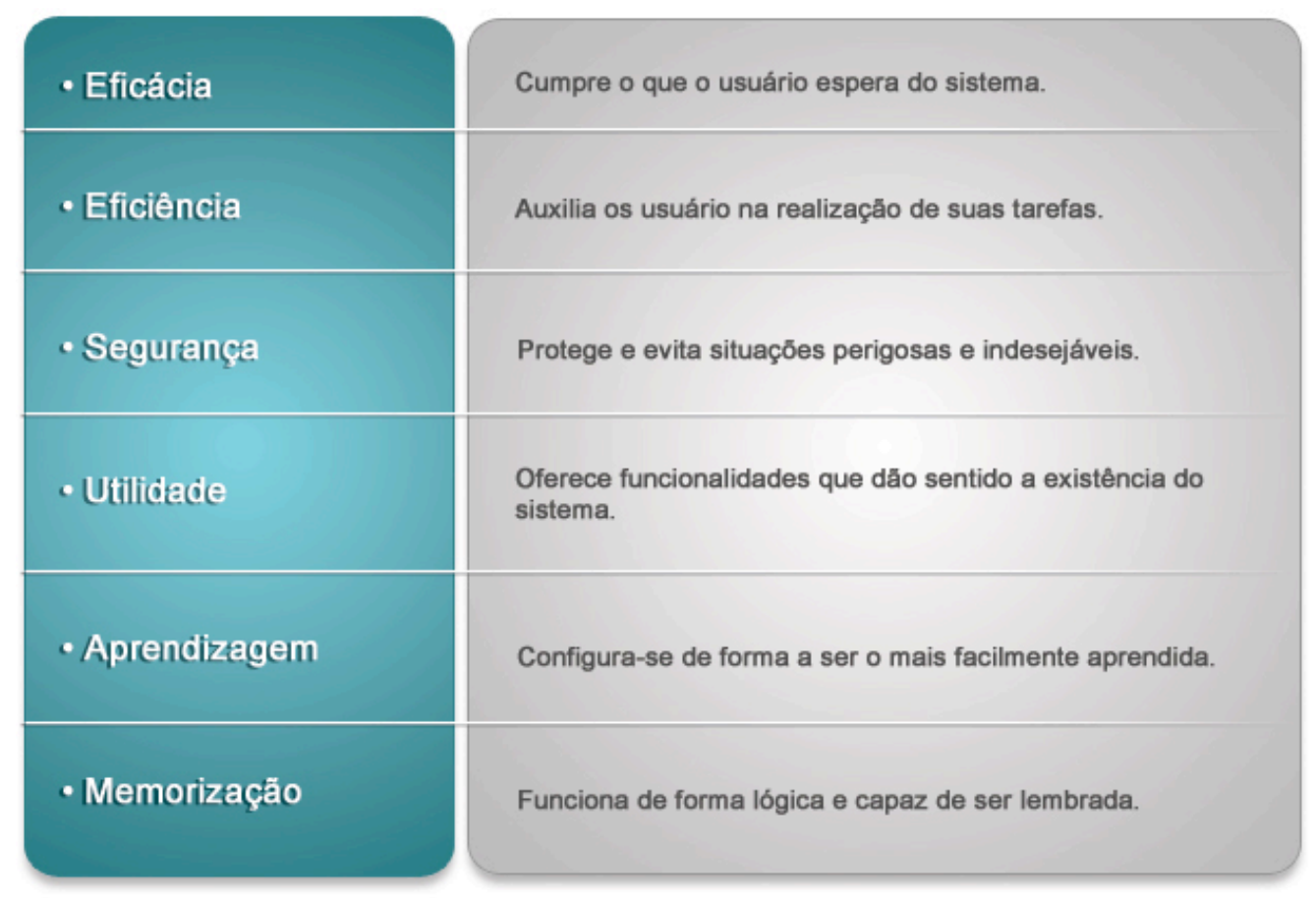

Figura 2 - Metas de Usabilidade

Fonte: Imagem desenvolvida baseada em dados de Preece et al. (2007)

Os princípios do design, segundo Preece et al. (2007), são chamados de heurística, de modo a enfatizar sua aplicação em um dado problema. A figura 3 mostra as heurísticas de usabilidade mais relevantes, segundo Castro e Tavares (2005), sendo relacionadas às metas de usabilidade de Preece et al. (2007). 
Os elementos mais relevantes precisam estar visíveis, destacados, principalmente os que possuem alguma açăo.

- Retorno (feedback)

\section{- Eficicácia}

Cada açăo deve ter uma reaçăo. Clicar num botăo implica numa indicaçăo de que ele foi pressionado.
- Constrangimentos
- Segurança

Os usuários podem possuir restriçס̄es para executar algumas açס̋es. É preciso evitar o seu constrangimentos perante esse fato.

- Consistência - Aprendizagem

Uma interface com consistência possui um padrăo de navegaçăo e por isso permite uma aprendizagem rápida e a diminuiçăo de erros.

\section{- Disponibilidade (affordances) - Eficiência}

As ferramentas de interaçăo precisam estar disponiveis. Indicadores de açăo ajudam a percepçăo de uso desses elementos.

- Mapeamento - Utilidade

Diz respeito a disposiçăo lógica dos elementos em relaçăo as suas funçōes.
- Cor
- Eficiência

A cor transmite senaçōes e significados. Seu uso possui impacto ao usuário e por isso serve para destacar informações, mas deve ser utilizado com prudência.

- Agrupamento de informação (chynking)

- Aprendizagem

Informaçōes dispostas de forma agrupada facilitam o entendimento, como por exemplo a leitura de um telefone em dois blocos de números.
- Proximidade
- Memorização

Elementos similares devem estar visualmente próximos.
- Efeito estética/usabilidade
- Eficiência

O uso da interface é facilitada pelas suas qualidades estéticas agradáveis.
- Sistemas de ajuda
- Segurança

Alternativas que ajudem os usuários a executarem uma tarefa, como a disponibilizaçăo de informaçס̋es extras ou atualizaçăo de software, minimizam o erro.

Figura 3 - Heurísticas de Usabilidade e sua Relação, à direita, com as Metas de Usabilidade Fonte: Imagem desenvolvida baseada em Castro e Tavares (2005) e Preece et al. (2007)

De acordo ao exposto, uma séria de apontamentos são feitos pelos autores quanto a utilização dos conceitos de usabilidade que cabem à de uma interface gráfica. Sua aplicação se torna complexa na medida em que todos os conceitos se interrelacionam e estão inseridos numa sistematização apresentadas objetivamente, tendo 
sua prática hibridizada com o ato da construção gráfica. Essa construção compete questões subjetivas, principalmente em relação ao usuário.

\section{EXPERIÊNCIA DO USUÁRIO E SUA BUSCA POR INFORMAÇÕES}

Segundo Preece et al.(2007), o objetivo do desenvolvimento de projetos interativos está na experiência que será proporcionada para o usuário. Sendo assim, algumas características como agradável, divertido, esteticamente apreciáveis, emocionalmente adequados possuem necessidade de estar na lista de requisitos de um projeto de interface gráfica. Estas características não são claramente definidas, elas são descobertas em estudos prévios focados no público alvo e devem ser levadas em conta na produção de projetos interativos.

ROYO(2008), sugere cinco princípios para que um sistema seja útil e fácil de usar mostrados na figura 4.

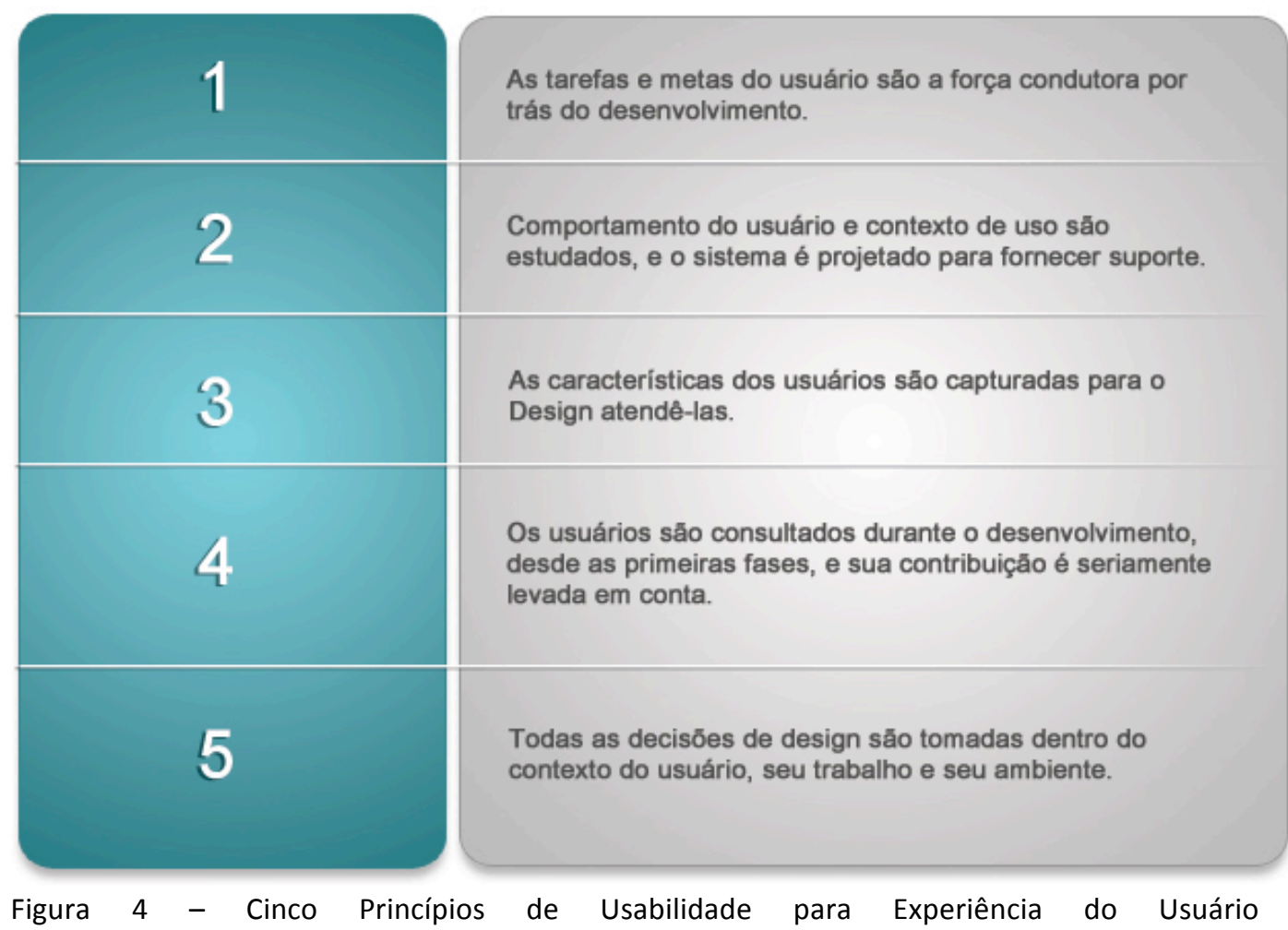

Fonte: Imagem desenvolvida baseada em Royo (2008).

Ainda de acordo com Royo (2008) a experiência do usuário é um conjunto, da experiência funcional juntamente com a experiência estética do produto. $E$ que ela, a experiência do usuário, é resultado dos objetivos do usuário, das variáveis culturais e do design de interface gráfica.

As variáveis culturais dependerão do conhecimento que o usuário tem de interfaces similares, e segundo Royo (2008, p. 105) “o usuário busca os conhecimentos em sua própria mente (conhecimento de mente) e no mundo (conhecimento do mundo) para interagir com o sistema" como mostra a figura 5. 

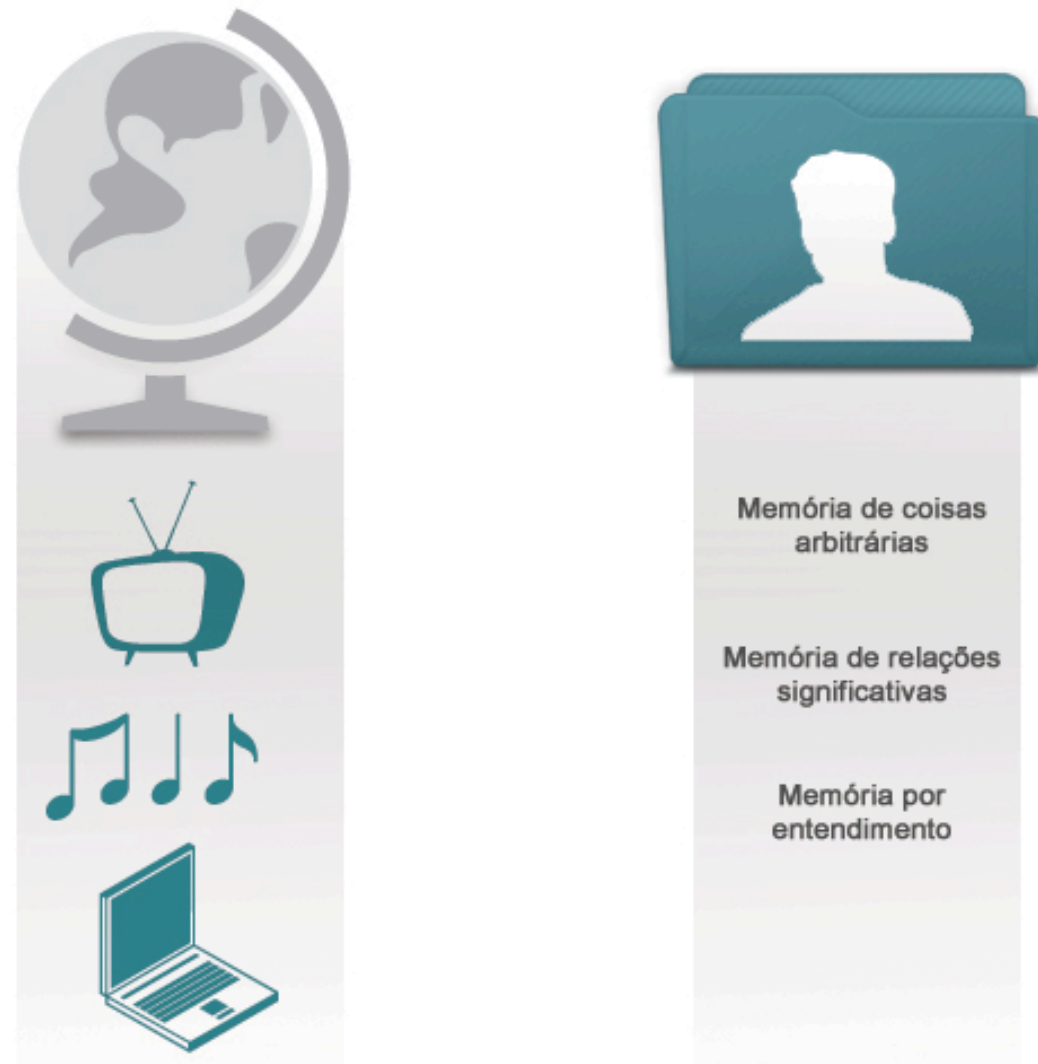

Memória de coisas arbitrárias

Memória de relações significativas

Memória por entendimento

Figura 5 - Conhecimento Mundo e Mente

Fonte: Imagem desenvolvida baseada em Royo (2008).

O conhecimento de mente é aquilo que já foi apresentado ao usuário e ficou registrado em sua memória. Conforme Norman (1990) existem três tipos de memória que o usuário utiliza dependendo das informações que precisa registrar:

- Memória de coisas arbitrárias: são as informações impostas a serem gravadas como por exemplo, uma senha de computador, teclas que devem ser apertadas para executar tal função, uma data de aniversário.

- Memória de relações significativas: utiliza memórias já inseridas no usuário para determiná-la para um novo sistema que será mais facilmente compreendido, como por exemplo utilizar uma interface já conhecida no mundo real que o usuário conseguirá utilizar por já conhecê-la.

- Memória por entendimento: pensando que para assimilar as informações o ser humano precisa compreendê-las essa memória é a de maior eficácia. Neste caso é necessário que o usuário encontre o significado do objeto pelas pistas dadas e faça a conexão do seu significado com o objeto.

Sendo então "conhecimento da mente" o aprendizado que fica gravado na memória, o ser humano também tem o conhecimento de mundo que pode ser chamado de memória externa. Essa memória externa são informações necessárias nas atividades diárias e não estão implícitas na mente, são como lembretes, anotadas para não serem esquecidas como calendários para situar a data, alarmes como lembrete de alguma reunião.

Em um projeto de interface gráfica, analisando o usuário envolvido, é necessário entender o contexto em que este interage com o sistema. $O$ entendimento 
desta interação segundo Preece et al. (2007), pode ser conhecido ao aplicar-se a etnografia. A etnografia pode ser traduzida como "descrever a cultura", ou seja, observar o usuário em seu ambiente de trabalho e encontrar uma ordem dentro de sua atividade. Esta observação pode ser feita através de conversas, reuniões, análise de documentos. Esta técnica é ideal para ser aplicada no começo do projeto, afirma Preece et al. (2010), para que seja descoberta qual é realmente a necessidade do usuário, é possível descobrir o que as pessoas realmente fazem, e não somente o que elas dizem que fazem.

\section{CONSIDERAÇÕES FINAIS}

Fica explícito a importância do Ergodesign e da engenharia de usabilidade, como fatores facilitadores para o usuário na busca pela informação em projetos de interface gráfica. A informação, por sua vez, é um conjunto de fatos organizados de tal forma que adquirem valor adicional além dos valor dos fatos em si. É necessário estabelecer regras e relações para transformar todos estes dados, em informações úteis e valiosas.

Sendo assim, entende-se que informação é um conjuntos de dados dotados de relevância e de propósito, e o tipo de informação criada depende fundamentalmente da relação definida entre os dados existentes. Concluindo que uma interface gráfica é muito mais do que um aspecto visual representado em uma tela, por trás existe um conceito a ser interpretado ao usuário. Facilitando o estudo em relação ao mesmo, que muitas vezes em um desenvolvimento de um projeto de interface gráfica ocorrem de maneira empírica. 


\section{REFERÊNCIAS}

ANDRADE, Antonio Luis Lordelo. Usabilidade de interfaces Web: Avaliação heurística no jornalismo on-line. Rio de Janeiro: E-papers, 2007.

CASTRO, Joana Isadora; TAVARES, João Manuel. Princípios relacionadoscom a ergonomia de sistemas multimédia - uma sistematização possível. Encontro Nacional de Visualização Cientifica - ENVC. Portugal, 2005.

CYBIS, W. A.; PIMENTA, M. S.; SILVEIRA, M. C.; GAMEZ, L. Uma Abordagem Ergonômica para o Desenvolvimento de Sistemas Interativos. Atas do I Workshop sobre Fatores Humanos em sistemas computacionais: compreendendo usuários, construindo interfaces - IHC'98, Rio de Janeiro, v. 1, p. 102-111, 1998.

DOMINGUES, Diana. Criação e interatividade na ciberarte. São Paulo: Experimento, 2002.

DUL, Jean; WEERDMEESTER, Bernard. Ergonomia Prática. 2. ed. São Paulo: Edgard Blücher, 2004.

FUENTES, Rodolfo. A prática do design gráfico. São Paulo: Rosari, 2006.

GRANDJEAN, Etienne. Ergonomics and health in modern offices. London, Taylor \& Francis, 1984.

IIDA, Itiro. Ergonomia: Projeto e Produção. 6. ed. São Paulo: Edgard Blücher, 2000.

KROEMER, Karl Elbert.; GRANDJEAN, Etienne. Manual de Ergonomia: adaptando o trabalho ao homem. 5. ed. Porto Alegre: Bookman, 2005.

LYNCH, Patrick; HORTON, Sarah. Manual de estilo web: principios de diseño básico para la creación de sitios web. 2. ed. Barcelona: Gustavo Gili, 2004.

MORAES, Ana Maria de; MONT'ALVÃO, Claudia. Ergonomia: conceitos e aplicações. 2. ed. Rio de Janeiro: 2AB, 1998.

MEMÓRIA, Felipe. Usabilidade de Interfaces e Arquitetura da Informação - Navegação Estrutural. 2o Congresso Internacional de Ergonomia e Usabilidade, Design de Interfaces e Interação Humano-Computador - USIHC. Rio de Janeiro, 2003.

MOURA, Mônica. A Interatividade no Design de Hipermídia. 70 Congresso de Pesquisa e Desenvolvimento em Design. Paraná, 2006. MONTMOLLIN, Maurice de. A Ergonomia. Lisboa: Instituto Piaget, 1990.

PREECE, Jennifer; ROGERS, Yvonne; SHARP, Helen. Design de interação: além da interação homem - computador. Porto Alegre: Bookman, 2007.

ROSA, José Guimarães Santa; MORAES, Anamaria de. Avaliação de projetos no design 
de interfaces. Teresópolis: $2 A B, 2008$.

ROYO, Javier. Design Digital. São Paulo: Rosari, 2008.

SANTOS, Robson. Ergodesign e Usabilidade de Interfaces para Sistemas de Informação. In Design: Gestão, Métodos, Projetos e Processos. Rio de Janeiro: Ciência Moderna, 2007.

YAP, Leong; VITALLIS, Tony; LEGG; Stephen. Ergodesign: from description to transformation. In Proceedings of the 13th triennial congresso of the International Ergonomics Association. Helsink: finnish Institute of Occupational Health, 1997. V.2, p.320-322. 